becoming one of the basic concepts Ukrainian musicology. Application of the conceptual apparatus of systemology allows researchers to comprehensively address the issues that are on the border of the theoretical, historical, performing musicology, extending the idea of the object of study.

Keywords: musicology, regional school, systemology, paradigm.

Стаття надійшла до редакції 13.04.2016

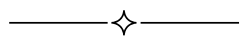

УДК $78.03+781.6$

\title{
A. Лаптева \\ ЖАНРОВЫЕ И СТИЛЕВЫЕ ОСОБЕННОСТИ CONCERTO GROSSO ДЛЯ СКРИПКИ И СТРУННЫХ ЮЛИИ ГОМЕЛЬСКОЙ
}

Произведение известного одесского композитора Ю. Гомельской является первым и единственным образцом данного жанра в украинской музыке и достойно представляет жанр Concerto grosso в мировой музыке. Написанный современным музыкальным языком и являясь новаторским в своей сущности, Concerto grosso не порывает с традициями, свойственными данному жанру, имеет скрытую программность, обнаруживающуюся в результате анализа и вдумчивого прослушивания.

Ключевые слова: Юлия Гомельская, Concerto grosso, скрипка, оркестр.

Цель данной статьи - анализ Concerto grosso для скрипки и струнных известного одесского композитора Юлии Гомельской, который является одним из немногих образцов данного жанра в Украине. Концерт был создан в 2009 году.

Как известно, Concerto grosso возник в последней четверти XVII столетия на базе трио-сонаты за счёт расширения её исполнительского состава, а также иных жанров: вокально-инструментального концерта венецианской школы рубежа XVI-XVII столетий, органной и оркестровой канцоны этих же веков. Таким образом, Concerto grosso имеет различные истоки, обнаруживая синтетическую свою сущность, что в высшей степени показательно для эпохи барокко, в которую и был создан данный жанр и в которой он достиг кульминации в своём развитии в рамках данной эпохи. Как указывает И. М. Ямпольский в Музыкальной энциклопедии, «первое произведение, основанное на принципах Concerto grosso, написал Алес- 
сандро Страделла (под названием «Sinfonia...», 1676)... Первые совершенные образцы Concerto grosso создал А. Корелли (около 1680, опубликованы посмертно в 1714)» [3, с. 932]. Concerto grosso Арканджело Корелли представляют собой циклические произведения, состоящие из четырёх - семи частей, контрастных между собой. Исполнительский состав чётко делится на две неравные группы: концертирующие инструменты (две скрипки и струнный бас - виолончель) и основная группа оркестра (ripieno - две скрипичные партии, альты и струнные басы с возможным участием клавишного инструмента - клавесина или органа, входящего в группу basso continuo), которые могут играть как все вместе одни и те же партии, так и противопоставляться друг другу. Очень удачно, на наш взгляд, определил сущность данного жанра А. Шеринг (первый исследователь истории инструментального концерта): «Мы обычно говорим о Concerto grosso там, где сопоставление двух звуковых масс становится принципом» (цит. по: [2, с. 8]).

В плане музыкальной формы и соотношения инструментальных партий в Concerto grosso никакой стабильности не наблюдается, наоборот, разнообразие культивируется. Роль струнного баса в группе concertino может быть весьма скромной при ведущей роли обеих скрипок, при совместной игре concertino и ripieni они могут сливаться друг с другом, а могут и значительно отличаться.

Для темы нашей работы существенно отметить, что возможен случай концертирования только одного инструмента из группы concertino, что воссоздаёт фактуру концерта для солирующего инструмента с оркестром - данное соотношение инструментов явно выступает в Concerto grosso Дж. Торелли op. 8 (изданы в 1709 г.). В результате культивируется, по словам теоретика барокко Г. Вёльфлина, «ценность изменения», столь присущая данной эпохе (см.: [2, с. 21]).

Существовала и иная разновидность большого концерта, в которой «концертирующая группа как бы растворяется в общем составе, лишь в необходимые моменты выходя вперёд» [1, с. 45]. Как видим, разнообразие оркестровых составов и фактуры в Concerto grosso является стилевой чертой данного жанра.

Важно также отметить, что Concerto grosso возник, как мы уже отмечали, в эпоху барокко, для которой, с одной стороны, центральной фигурой становится личность, а с другой - «ощущение безвозвратного разрыва с прошлым, и крушение ренессансных идеалов. Сами 
исторические события, казалось, стремились разрушить гармонию мира и человека...» $[2$, с. 9]. Эпохе барокко, как известно, свойственно трагическое мироощущение.

Несколько позже Concerto grosso (на рубеже XVII-XVIII столетий) возникает сольный концерт для скрипки с оркестром - в творчестве Дж. Торелли и особенно А. Вивальди, в котором уже один солирующий инструмент противопоставляется оркестру. Но и в данном типе концерта встречаются случаи концертирования инструментов оркестра, сближаясь в этих моментах с concerto grosso. Концерт для солирующего инструмента с оркестром прокладывает путь к утверждению классицизма, для зрелого этапа которого данный тип концерта чрезвычайно показателен. Concerto grosso же во второй половине XVIII и XIX столетиях исчезает из композиторской практики вообще, возрождаясь в XX веке в рамках неоклассицистского направления. Concerto grosso возникает в творчестве М. Регера, Г. Каминского, О. Респиги, Э. Кшенека, Б. Мартину, А. Казеллы, В. Хаэта, Э. Блоха, К. Пендерецкого, Ф. Гласса, М. Чекалина, А. Шнитке... К жанpy Concerto grosso примыкают и так называемый «Эбонитовый» концерт И. Стравинского, и концерты В. Фортнера и Э. Тамберга... Часто к жанровому названию Concerto grosso прибавляется и уточнение, связанное с составом концертирующей группы инструментов или выделением солирующего. Так, у В. Хаэта (кстати, учившегося в Одесской консерватории и окончившего её в первом выпуске - в 1918 году) - Concerto grosso для фортепиано с оркестром, К. Пендерецкого - Concerto grosso для трёх виолончелей с оркестром.

В украинской музыке обращения к Concerto grosso немногочисленны: произведения в данном жанре имеются у Г. Таранова, В. Губаренко, Д. Киценко, 3. Алмаши; одесский композитор А. Красотов создал Concertino grosso для виолончельного дуэта и камерного оркестра в пяти частях.

Жанровое название Концерта Ю. Гомельской - Concerto grosso для скрипки и струнных, как видим, не является исключением. Для уточнения и понимания жанровой специфики Концерта особое внимание следует уделить анализу соотношений как концертирующего инструмента с оркестром, так и партий струнного оркестра между собой. Задействованный инструментальный состав выбран далеко не случайно: он, как мы покажем, обусловлен концепцией Концерта. Сразу же обращает на себя внимание противопоставление солирующей скрипки струнной группе. Голос солирующей скрипки ассоциирует- 
ся с личностью - ищущей, размышляющей, страдающей, любящей, борющейся, противопоставляемой окружающей её среде, которую представляет струнная группа оркестра. Концерт насыщен борьбой, полной драматизма и всевозможных перипетий. Данная концепция имеет ярко выраженную романтическую окраску; учитывая средства современного музыкального языка Концерта, можно определить и художественное направление, к которому он принадлежит: это синтез неоромантизма (по концепции) и экспрессионизма (по средствам музыкальной выразительности), органически сочетающихся в произведении. По жанру же Концерт - лирико-драматический.

Концерт одночастный, что достаточно типично для современных образцов не только данного жанра, но и тех произведений, которые имеют циклическую природу. Начиная с симфонических поэм Ф. Листа, одночастных с точки зрения музыкальной формы (при наличии скрытой цикличности), получают широкое распространение в музыке XX столетия именно как одночастные - симфонии, симфониетты, сонаты, концерты, различные по своему составу камерноинструментальные жанры. Форма Концерта свободная, состоящая из ряда разделов, в ней имеются лейтинтонации и музыкально-тематические повторения, цементирующие форму произведения в целом и создающие определённую драматургию, основанную на чередовании эпизодов только солирующей скрипки и струнной группы оркестра вместе с ней. Скрипка может звучать соло, то есть при паузировании оркестра, преобладать в общем звучании (оркестр играет роль сопровождения), быть равноправным компонентом в противостоянии с ripieno. В отдельных, достаточно редких случаях оркестр выходит на первый план при паузировании солиста. Партии оркестра равноправны между собой: им в равной степени поручается проведение важных тем, большую роль играют и полифонические приёмы, охватывающие все оркестровые партии. В этом также заключается специфика жанра Concerto grosso в отличие от концерта для солирующего инструмента с оркестром.

Концерт Ю. Гомельской основан на тональном мышлении с использованием расширенной тональности, столь свойственной гармонии XX столетия.

Концерт открывает острое конфликтное противостояние солирующей скрипки и струнных (пример 1). Композитор подчёркивает это всеми выразительными средствами: после трёхтактного звучания скрипки соло со стремительным взлётом вверх, ассоциирующимся 
со стремлением вырваться из негативной сферы, представленной трелью на $a s$, к возвышенной $\left(f^{2}\right)$, вступает струнная группа с многократно повторяемым аккордом ${ }^{1}$, основанным на кластере (заметим, что кластерные звучания в произведении играют существенную роль, выполняя как колористическую, так и драматизирующую функции), в котором звуки фригийского лада от $e$ за исключением $c$ (VI ступени) звучат одновременно, образуя весьма жёстко звучащее созвучие.

\section{Пример 1}

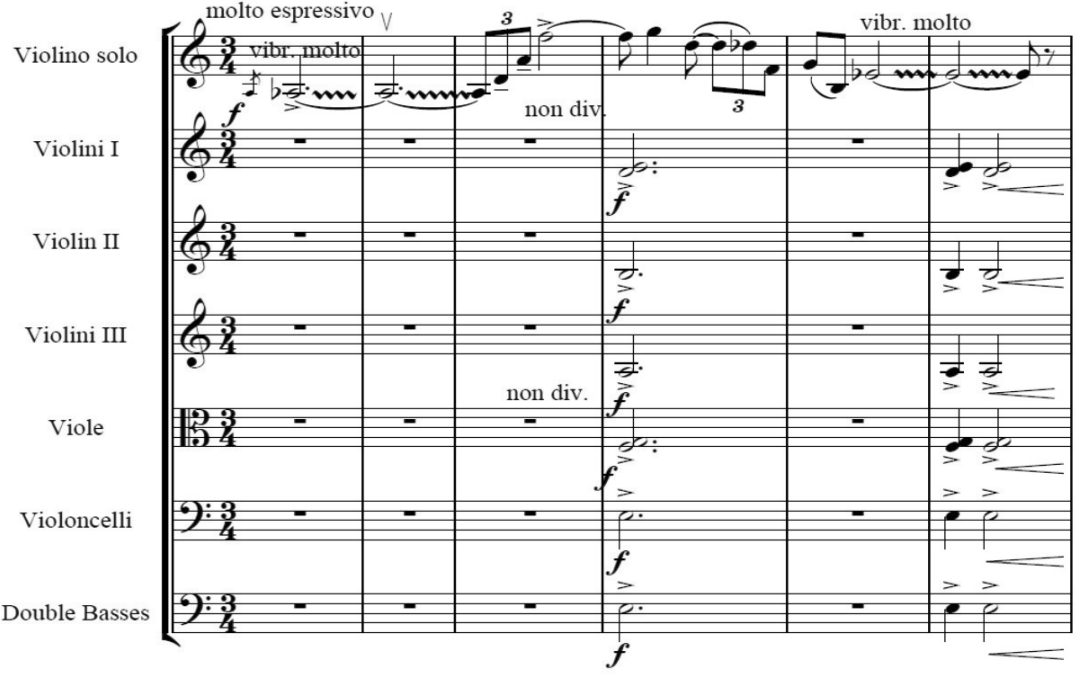

Последующие аккорды звучат ещё более диссонантно, что подчёркивается и распределением звуков по инструментальным партиям, и конкретным расположением аккордов, и артикуляцией - штрих marcato. В этом отношении особенно остро звучит последний аккорд, воспринимаемый как доминантовый (формально это доминантовый нонаккорд фригийского лада с внедряющимся тоном - квартой). Кластерное звучание всех звуков фригийского лада, тоже без VI ступени, образуется уже от $h$, причём основной тон утраивается - он поручен не только струнным басам, но и альтам, образуя трёхоктав-

${ }^{1}$ Термин «аккорд» мы употребляем, конечно, в современном его значении как созвучия, звуки которого образуют определённую систему; в данном случае все аккорды вступления имеют в своей основе кластер. 
ное звучание, что ещё больше подчёркивает конфликтную природу данного созвучия (пример 2). Таким образом, струнные выступают здесь как сила, противоборствующая личности, пытающейся достичь своих идеальных представлений (эта аккордовая последовательность будут повторена с некоторыми изменениями в заключительном разделе Концерта). Вступительная же часть Концерта служит эпиграфом ко всему произведению, чётко передавая конфликт, разворачивающийся на протяжении всего Концерта.

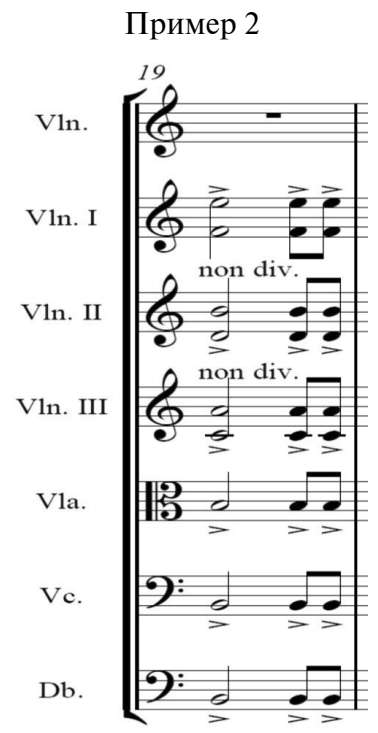

С 20-го такта у солирующей скрипки проводится важная тема, звучащая и в финале Концерта. Она строится на опевании основного звука $f$ малой и большой секундами, а также малой терцией с последующим восходящим ходом на сексту. Данная тема играет существенную роль в интонационной драматургии произведения (пример 3). Возникают ассоциации и со знаменным распевом, и с глубоко национальными песенными и романсовыми интонациями, а также с начальной темой Третьей симфонии С. В. Рахманинова.

Намеченный конфликт солирующей скрипки и струнной группы получает развитие и далее, однако противостояние по степени остроты подвижно - оно постоянно меняется. Так, после небольшого монолога солирующей скрипки, полного экспрессии, насыщенного 
скачками на септимы и ноны (такты 35-45), аккорды струнной группы смягчаются, скрипки и альты звучат с сурдинами, dolce cantabile, на pianissimo, кластеры звучат как мягкое колористическое средство (такты 46-53). В это же время скрипка соло продолжает свой монолог, тематическим зерном которого является восходящий тетрахорд с последующим его последовательным перемещением то вверх, то вниз. Стремление вознестись вверх, к высокой духовной сфере сохраняется, однако в данном эпизоде тесситура солирующей скрипки постепенно понижается, идёт спад. Неоднократно звучащий ход на увеличенную квинту вниз с последующим разрешением основания интервала (пример 4) и последовательное перемещение данного мотива, приобретающего значение лейтинтонации, показывает всю сложность процесса достижения идеала (в последнем проведении данного хода увеличенная квинта заменяется чистой).

Пример 3

$\operatorname{Vin}$.

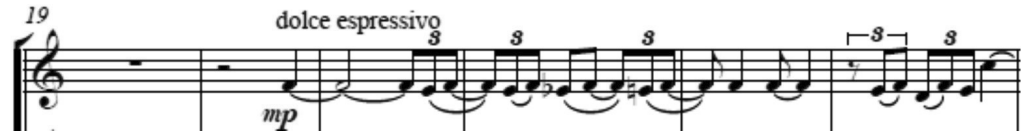

Пример 4

Vln.

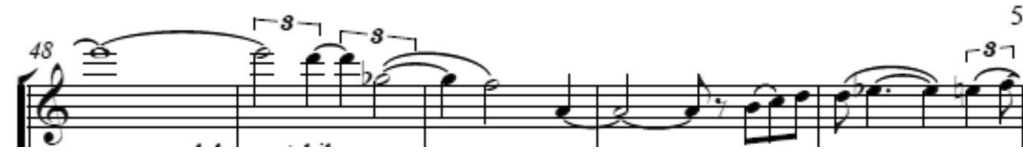

Эпизод завершается в 76 такте длительным звучанием почти самого низкого звука скрипки - as. Струнная же группа наделяется функцией сопровождения солирующей скрипки. Однако скрытое противостояние ощущается, так как в гармоническом отношении солирующая скрипка не сливается ни с одной из партий оркестра, которые индивидуализируются, становятся более самостоятельными, отходя от аккордовой фактуры, присущей эпиграфу.

С последней доли 76-го такта начинается новая фаза в развитии Концерта (по 118-й такт): струнная группа уже не противопоставлена солирующей скрипке, а образует некое единство в образном отношении. Однако в тематическом отношении имеется контраст: в оркестре формируется новая тема, которая, начинаясь на pianissimo, по- 
степенно разрастается, обогащаясь подголосками (пример 5). Тем не менее её новизна относительна: тема вытекает из уже знакомого нам тетрахорда, неоднократно повторяющегося солирующей скрипкой, только тут он проходит в увеличении. Таким образом обеспечивается тематическое единство, а дальнейшее противостояние приобретает характер единства и борьбы противоположностей.

Пример 5

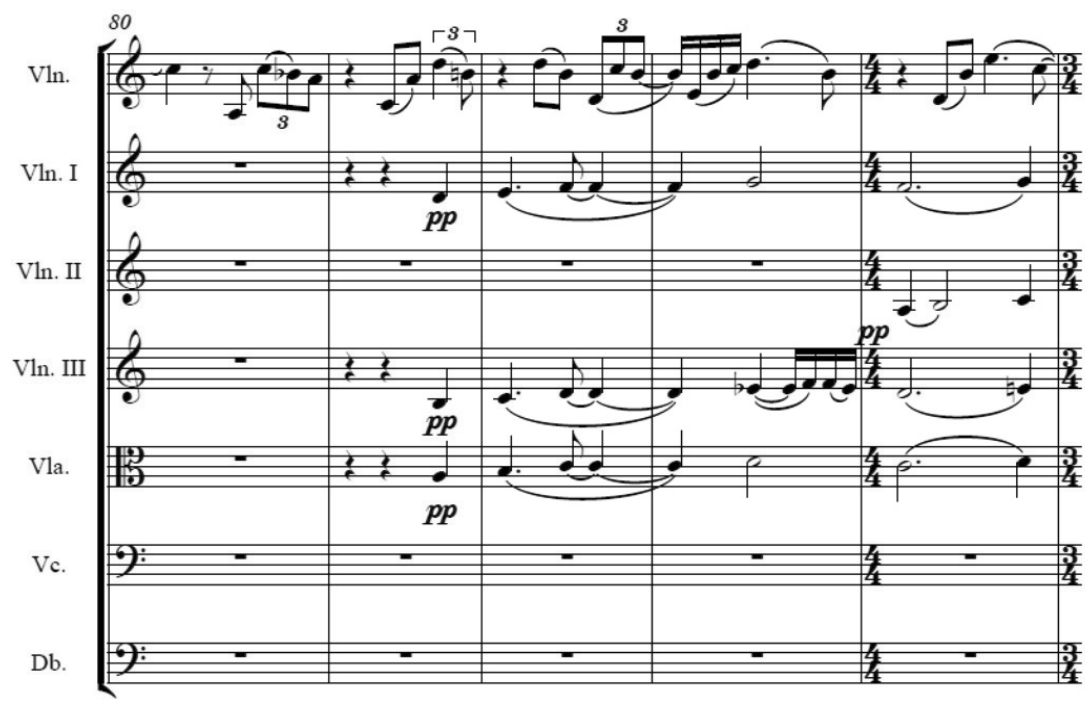

Партии первых и третьих скрипок с альтами образуют движение параллельными созвучиями, включая секунды, острые диссонансы, тематический контраст солирующей скрипки и оркестра. Эти средства свидетельствуют о том, что конфликтное начало ничуть не преодолено, но оно пока выступает в затаённом виде. Дальнейшее развитие обогащается полифоническими приёмами в виде свободных имитаций. Звучание становится всё более насыщенным и напряжённым, особенно после вступления контрабасов. Оркестр охвачен секвенционным восходящим движением, в основе которого лежит восходящий тетрахорд, приобретающий значение лейттематического комплекса. Напряжённости звучания способствует параллельное движение струнных весьма сложными кластерными созвучиями. Все голоса оркестра вместе с солирующей скрипкой устремлены вверх, 
достигая кульминационного звучания на fortissimo. Таким образом, весь этот эпизод представляет собой длительное нарастание по динамике и напряжённости звучания. После генеральной паузы (такт 119) наступает новая фаза в развитии: движение к идеалу не завершилось его утверждением и, значит, достижением. Тихий срыв с постепенным понижением общей тесситуры звучания (такты 120-124) свидетельствуют об обратном (пример 6).

Пример 6

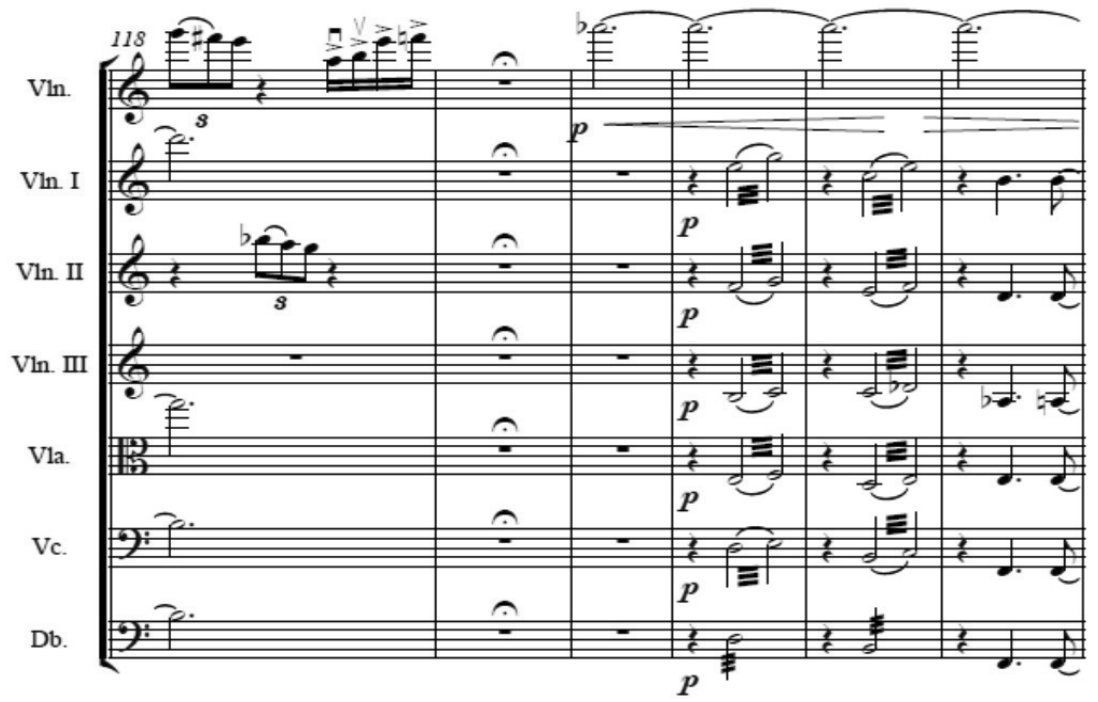

После небольшого, но напряжённого монолога солирующей скрипки (такты 126-135), полного мучительных раздумий, перекликающегося с предшествующим аналогичным её высказыванием (такты 35-45), следует новый эпизод (такты 136-151), насыщенный более острым противостоянием и борьбой, нежели это было ранее. Страстному высказыванию скрипки с синкопированным движением, насыщенным скачками на широкие интервалы, создающими особую экспрессию, противостоят вскоре вступающие струнные басы с этой же темой, однако контраст регистров и тембра создаёт впечатление конфликта и драматизирует образ. Остальные голоса оркестра образуют беспокойный подвижный фон с полиритмией, что ещё более усиливает напряжённость. Следующее сольное высказывание скрипки 
(такты 152-154) сопровождается отдельными аккордами оркестра, то есть возникает новый тип фактуры, не встречающийся ранее в Концерте. Стремительное движение скрипки плавно переходит в следующий эпизод Концерта (такты 155-171). И солирующая скрипка, и оркестровые партии устремлены вверх при всём различии в их типах движения: стремительному бегу шестнадцатых скрипки противостоит постепенный гаммообразный подъём струнных, то есть в основе их тематизма лежат уже знакомые нам восходящие тетрахорды. Здесь происходит дифференциация оркестровых партий: скрипки (три партии) противопоставлены струнным басам с альтами. Имея единую интонационную основу, они не совпадают по метроритму. Со 163-го такта басовые инструменты перенимают у солирующего движение шестнадцатыми, а у скрипки уже движение тридцать вторыми - общее ритмическое движение учащается и вследствие этого напряжение возрастает. В следующем эпизоде (такты 173-185) ведущую роль играет солирующая скрипка, что свидетельствует о победе личности. Оркестровые струнные ограничиваются только отдельными репликами, но яростными протестующими - борьба продолжается. Но со 188-го такта у солирующей скрипки звучит яркая мелодия на piano - личность побеждает не благодаря грубой силе, а благодаря своим качествам, основанным на высоких нравственных представлениях.

В следующем эпизоде (с 202-го такта) начинается дальнейшая фаза борьбы. Здесь противостояние выражено в последовательном чередовании различных высказываний солирующей скрипки (pizzicato, отрывистыми двойными нотами, glissando) и вначале затаённого звучания струнной группы sul ponticello на pianissimo, воспринимающегося как некий шорох. После двух подобных проведений струнная группа обретает всю свою мощь, звуча уже в полную силу на fortissimo ordinario с басовыми инструментами. На короткое время оркестр выходит на первый план. В оркестровых партиях встречается и pizzicato, и glissando. Но солист не отступает, смело «бросаясь в бой». Борьба достигает своего апогея (такты 234-245). В партии солирующей скрипки получает развитие тема из вступительного раздела Концерта, основанная на опевании опорного тона (см. пример 3), только сейчас она проходит в октаву на fortissimo. Затем у струнных басов и первых скрипок возникает грозно звучащая тема, интонационно схожая с мелодией, проводимой в это же время солистом, но имеющая иное семантическое значение - опять возникает борьба противоположностей. Подвижный фон создают остальные инструменты оркестра со 
своими беспокойными фигурациями. Это генеральная кульминация всего Концерта. После неё поникше звучат реплики струнной группы на pianissimo, символизируя своё поражение.

C 252 такта возникает репризный эпизод Meno mosso, соответствующий разделу начальной фазы противостояния (с 46-го такта, dolce cantabile), однако с совершенно иной в тематическом отношении партией солиста. Тему, которую вела солирующая скрипка, теперь проводят виолончели. Обе темы связаны друг с другом, являясь свободным обрашением их самих (пример 7).

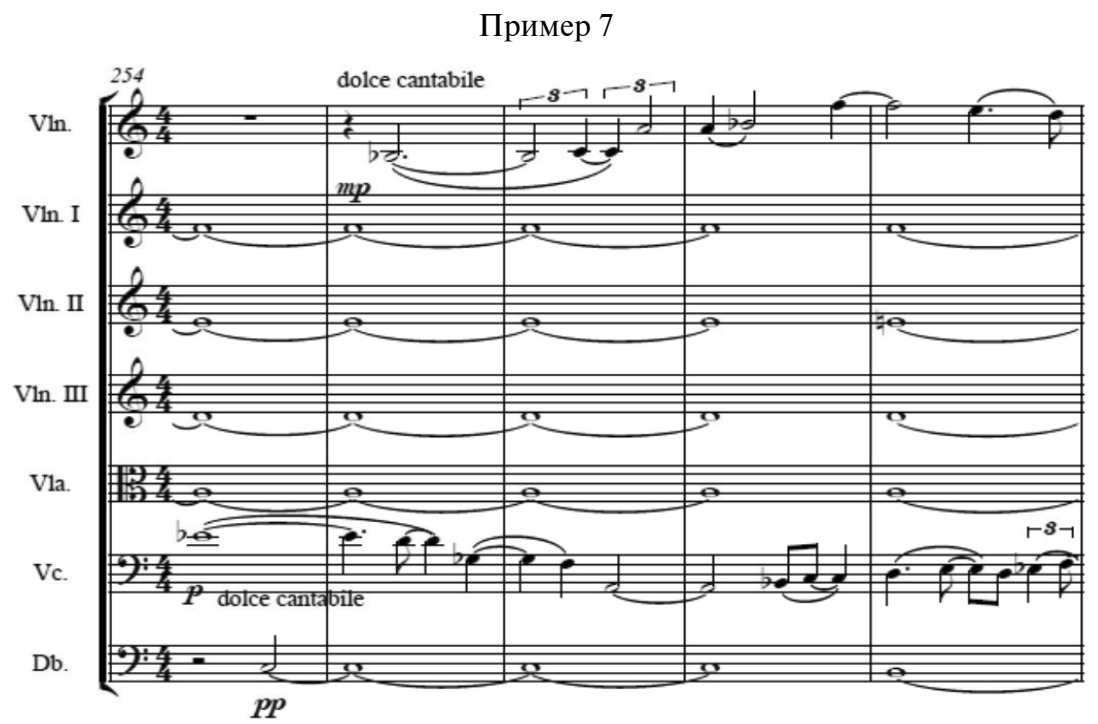

Далее приобретает активность и партия альтов, которая также интонирует тему, прозвучавшую у виолончелей. Дальнейшее развитие в этом эпизоде приводит к нарастанию звучания, но не достигающего, однако, прежнего напряжения.

С 286-го такта наступает заключительная стадия развития. Противостояние солиста и оркестра растворяется при явном доминировании первого. Тематические элементы, проводимые солистом, подхватываются и развиваются оркестровыми партиями. О противостоянии напоминают протяжённые линии (с 311-го такта) у струнных басов, альтов, а затем и у третьих и вторых скрипок, в то время как первые ведут диалог с солистом. Длительное нарастание приводит к прове- 
дению у оркестра с незначительными изменениями аккордовой последовательности (такты 359-364), звучавшей в эпиграфе, - силы, противостоящие личности, не сдаются. И в результате происходит ещё один «взрыв» (с такта 365). В основе оркестровых партий лежит тема, впервые проходившая в начальном эпизоде Концерта (с такта 81), - противостояние не завершено, борьба разгорается с новой силой. Однако, достигнув кульминации (такты 403-408), она очень быстро идёт на спад. Наступает кода (с такта 417, Poco meno mosso). Оркестр замирает на трёх рiano, и после флажолетного звучания солирующей скрипки в её же партии проходит тема, основанная на опевании опорного тона, уже неоднократно звучавшая в Концерте и символизирующая личностное начало. Тихим, проникновенным звучанием завершается всё произведение: на фоне колористического кластерного звучания струнных оркестра у солирующей скрипки звучит на pianissimo фраза, в которой важную роль играет дважды повторенный восходящий ход на малую сексту - интервал, играющий существенную роль во всём Концерте.

Итак, как видим, Concerto grosso для скрипки и струнных Ю. Гомельской обнаруживает скрытую программность, в основе которой, как предполагается, - противостояние личности и окружающей среды, заканчивающееся примирением человека с ней без отступления от своих принципов. Личность не одерживает победы, не торжествует, но она остаётся несломленной. В завершении произведения достигается гармония в результате весьма напряжённой борьбы.

Представляется также, что Concerto grosso для скрипки и струнных Ю. Гомельской, являясь одним из немногих образцов данного жанра в украинской музыке, вносит достойный вклад не только в отечественное искусство, но и в мировое.

\section{СПИСОК ЛИТЕРАТУРЫ}

1. Гинзбург Л. С., Григорьев В. Ю. История скрипичного искусства в трёх выпусках. Вып. 1 / Л. С. Гинзбург, В. Ю. Григорьев. - М.: Музыка, 1990. $285 \mathrm{c}$.

2. Зейфас Н. М. Concerto grosso в творчестве Генделя / Н. М. Зейфас. М.: Музыка, 1980. - 80 с.

3. Ямпольский И. М. Concerto grosso / И. М. Ямпольский // Музыкальная энциклопедия: в 6 томах / гл. ред. Ю. В. Келдыш. - М.: Советская энциклопедия, 1973-1982. - Т. 2. - С. 932-933. 
Лаптева А. Жанрові і стильові особливості Concerto grosso для скрипки $\boldsymbol{i}$ струнних Юлії Гомельської. Твір відомого одеського композитора Ю. Гомельської є одним з небагатьох зразков цього жанру в українській музиці і гідно представляє Concerto grosso в світовій музиці. Написаний сучасною музичною мовою і будучи новаторським по своїй суті, Concerto grosso пориває з традиціями, властивим даному жанру та має приховану програмність, що виявляється у результаті аналізу та вдумливого прослуховування.

Ключові слова: Юлія Гомельська, Concerto grosso, скрипка, оркестр.

Lapteva A. Genre and style peculiarities of Concerto grosso for violin and string by Iuliia Gomelskaya. The work of a known Odessa composer Iuliiya Gomelskaya is one of few examples of this genre in the Ukrainian music and honorably represents Concerto grosso in the world music. The used modern musical language and being novel in its quintessence, Concerto grosso does not break away from tradition peculiar for this genre and possess a latent program revealed in the course of analysis and thoughtful listening.

Keywords: Iuliia Gomelskaya, Concerto grosso, violin, orchestra.

Стаття надійшла до редакції 20.04.2016

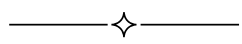

УДК 78.01+78.071.2

\section{O. Epziєва}

\section{ЕМОЦІЙНИЙ ІНТЕЛЕКТ МУЗИКАНТА-ІНСТРУМЕНТАЛІСТА І ТРАНЗИТИВНІСТЬ ХУДОЖНЬО-ЕСТЕТИЧНИХ ЕМОЦІЙ В КОНЦЕРТНО-КОМУНІКАТИВНІЙ СИТУАЦІЇ}

У статті розроблено проблему впливу емоційного інтелекту на транзитивність художньо-естетичного смислу музичного твору в процесі його виконання в сучасній жанрово-стилістичній концертно-комунікативній ситуації. Вказані методи розвитку емоційного інтелекту музиканта як важливої складової артистичної техніки виконавия. Виявлено три щаблі розвитку емоційного інтелекту, які сприяють успішній творчій реалізації музиканта в соціумі.

Ключові слова: асоціювання, візуалізація, відпускання емоцій, депрограмування, емоційний інтелект, емоційне мислення, емоційна обдарованість, емоційний словник, перепрограмування.

Як відомо широкому колу композиторів, виконавців, мистецтвознавців, кінець XX - початок XXI століття були позначені бурхливим розвитком виконавського музикознавства, відміченим рефлек-

(C) Єргієва О., 2016 